Georgetown University Law Center

Scholarship @ GEORGETOWN LAW

2009

\title{
Improving Laws and Legal Authorities for Obesity Prevention and Control
}

Lawrence O. Gostin

Georgetown University Law Center, gostin@law.georgetown.edu

Jennifer L. Pomeranz

Yale University

Georgetown Public Law and Legal Theory Research Paper No. 10-79

This paper can be downloaded free of charge from:

https://scholarship.law.georgetown.edu/facpub/486

http://ssrn.com/abstract $=1729227$

37 J.L. Med. \& Ethics 62-75 (Supp. 1 2009)

This open-access article is brought to you by the Georgetown Law Library. Posted with permission of the author.

Follow this and additional works at: https://scholarship.law.georgetown.edu/facpub

Part of the Health Law and Policy Commons 


\title{
Improving Laws and Legal Authorities for Obesity Prevention and Control
}

\author{
Jennifer L. Pomeranz and Lawrence O. Gostin
}

$\mathrm{T}$ This paper is one of four interrelated action papers resulting from the 2008 National Summit on Legal Preparedness for Obesity Prevention and Control. Summit participants engaged in discussions on the current state of the law with respect to obesity, nutrition and food policy, physical activity, and physical education. Participants also identified gaps in the law at all jurisdictional levels and relevant to numerous sectors and disciplines that have a stake in obesity prevention and control.

The companion paper, "Assessment of Laws and Legal Authorities for Obesity Prevention and Control," identified numerous laws and policies enacted to target the three domains of healthy lifestyles, healthy places, and healthy societies. ${ }^{1}$ That paper identified several gaps in the law that require attention and action. This paper addresses those gaps and presents applicable laws and legal authorities that public health professionals and lawyers can consider to implement to close the gaps.

Public health legal preparedness is the "attainment by a public health system of specified legal benchmarks or standards essential to the preparedness of the public health system."' Public health systems vary depending on the health issue confronted but nearly always include public health and legal practitioners along with relevant setting and sector stakeholders.
The goal of this paper is to present action items for law and policymakers and public health practitioners at the federal, tribal, state, local, and community levels to consider when developing, implementing, and evaluating obesity prevention and control strategies and interventions.

This paper will define legal action items for those working within the different public health systems to use to assure the conditions in which people can be healthy. Like the companion paper, this paper is divided by the three vital domains: Healthy Lifestyles, Healthy Places, and Healthy Societies. Specific action options are provided under each domain and the table provides a broader list of relevant options developed at the Summit.

\section{Healthy Lifestyles}

Healthy lifestyles exist when the environment facilitates physical activity and healthy food choices. ${ }^{3}$ The goal of this domain is to make the default environment one that fosters healthy lifestyles.

\section{Access to Healthy Food}

The overarching contributors to choosing healthy foods are the cost, quantity, and quality of the food supply. One factor to the general make-up and relative pricing of food in the U.S. is due in large part to the farm subsidies established and maintained under

Jennifer L. Pomeranz, J.D., M.P.H., is the Director of Legal Initiatives at the Rudd Center for Food Policy and Obesity at Yale University. Her work is dedicated to finding legal solutions to public health issues and most recently published on the topics of food marketing to children, menu labeling, and weight bias. She earned her Juris Doctorate from Cornell Law School in Ithaca, New York, and her Masters of Public Health from the Harvard School of Public Health in Boston, Massachusetts. Lawrence 0. Gostin, J.D., LL.D. (Hon.), is the Linda D. and Timothy J. O'Neill Professor of Global Health Law, the Faculty Director of the O'Neill Institute for National and Global Health Law, and Professor of Public Health at the Johns Hopkins University. Dean Gostin has an honorary doctor of laws from the State University of New York, New York, and an honorary fellow from the Cardiff University, Wales. 
the Farm Bill. Under this crucial piece of legislation, the USDA provides substantial agricultural subsidies, ${ }^{4}$ primarily for major commodity crops such as corn, soy, wheat, and cotton. ${ }^{5}$ As a result, these crops are available in a relative abundance, and this drives down their price as well as that of the foods and beverages manufactured with them and livestock reared on them. The overabundance and economic incentives to eat calorie-dense, nutrient-poor foods have proven to be obesogenic and a contributor to the public health problems in the country. From 1985 to 2000 , the price of fruits and vegetables in the U.S. rose $117 \%$, compared to $46 \%$ for sweets and desserts and $20 \%$ for soft drinks. ${ }^{6}$

Reconsideration of farm subsidies has been raised fervently in recent years and Summit participants advocated subsidizing a variety of vegetables and fruits, and foods such as nuts, legumes, and animals raised on food they naturally eat (instead of corn), in order to shift the U.S. diet in a healthier direction. Studies in Iowa show that farmers who produce commodity crops operate at a net loss ${ }^{7}$ and that both farmers and the state's economy would benefit from increasing the production of fruit and vegetables, ${ }^{8}$ which could also result in decreased produce prices and increased consumption.

However, states and local governments need not wait on the reauthorization of the federal Farm Bill to encourage healthy lifestyles in their communities. The food environment - i.e., the ratio of fast food restaurants to grocery stores to convenience stores, access to and availability of fresh food, prevalence of liquor stores and food desserts - contributes to, or is a barrier to healthy eating and a healthy weight. ${ }^{9}$ Low-income communities have one-third to one-half the number of supermarkets found in more affluent neighborhoods, but twice as many small markets or corner stores that are less likely to carry produce and other healthy items and are often relatively more expensive. ${ }^{10}$ Studies show that the proximity one lives to stores that carry fresh vegetables is positively related to the person's intake of vegetables. ${ }^{11}$ Conversely, fastfood outlets across neighborhoods are negatively associated with residents' health outcomes, in that a greater distribution of fast-food restaurants is associated with a greater prevalence of overweight/obesity among neighborhood residents. ${ }^{12}$

The built environment is composed of several relevant variables including the land-use mix, street connectivity, the accessibility of fast-food outlets, grocery stores, farmers' markets, public transit stations, and green and open spaces - all malleable by local governments. ${ }^{13}$ Applicable legal action items are discussed further in the Healthy Places section.

\section{Marketing}

The Federal Trade Commission (FTC) subpoenaed 44 food and beverage companies to analyze their marketing practices directed at children and adolescents ${ }^{14}$ and found that they spent almost $\$ 2$ billion targeting youth in 2006 alone. ${ }^{15}$ Critically, the FTC found that carbonated beverages, quick service restaurant food and breakfast cereals accounted for $65 \%$ of the total amount spent on marketing to youth ages 2-17 by these companies..$^{16}$ The associated food and beverages are most often nutrient poor but high in saturated fat, sugar, and sodium. This is concerning because studies indicate that food advertising increases children's consumption of advertised foods in the short term, children's preferences for the foods advertised, and their requests to parents for those foods at both the brand and the category level. ${ }^{17}$

Although the FTC is the federal agency responsible for regulating the advertisement of foods and beverages, ${ }^{18}$ it does not have the authority to regulate unfair marketing practices directed at children. In 1978, the FTC initiated proposed rulemaking, called KidVid, based on the evidence that the televised advertising of sugared products to children of all ages may be unfair and deceptive under the FTC Act. ${ }^{19}$ In the face of strong opposition, Congress withdrew the FTC's authority to regulate advertising to children under the "unfair" prong of the FTC Act and this regulatory gap remains today. ${ }^{20}$ However, the FTC retains authority to promulgate rules on the subject under the "deceptive" prong of the Act. ${ }^{21}$ The FTC has not attempted such action.

Scientific evidence strongly suggests that the FTC should utilize its authority to regulate marketing to children as deceptive..$^{22}$ The IOM found that " $[\mathrm{m}]$ ost children ages 8 years and under do not effectively comprehend the persuasive intent of marketing messages, and most children ages 4 years and under cannot consistently discriminate between television advertising and programming." ${ }^{23}$ Likewise, the American Psychological Association's Task Force on Advertising and Children found that "[c]hildren below age 7-8 years tend to accept commercial claims and appeals as truthful and accurate because they fail to comprehend the advertiser's motive to exaggerate and embellish.".24 Even for older children, newer forms of marketing, including product placements, viral marketing, and sponsorships deactivate their ability to process advertising information, thereby reducing potential skepticism and other defenses. ${ }^{25}$ In addition, the FTC's ability to protect children from unfair marketing practices should be restored so it can address the reality of the current marketing environment. 
Table

\section{Improving Laws and Legal Authorities}

\begin{tabular}{|c|c|c|c|}
\hline $\begin{array}{l}\text { LAWS/REGULATIONS/ } \\
\text { POLICIES }\end{array}$ & PUBLIC HEALTH ISSUE & SETTING & BEHAVIOR AREA \\
\hline $\begin{array}{l}\text { Americans with Disabilities Act } \\
\text { (ADA) }\end{array}$ & $\begin{array}{l}\text { Civil rights protections to individuals with disabilities } \\
\text { in the areas of public accomodation, public services, } \\
\text { transportation, education, employment, and telecom- } \\
\text { munication }\end{array}$ & $\begin{array}{l}\text { Community; Health } \\
\text { care; Schools; Worksites }\end{array}$ & $\begin{array}{l}\text { Social justice: health access, } \\
\text { health disparities, disability }\end{array}$ \\
\hline Breastfeeding Promotion Program & $\begin{array}{l}\text { Encourages breastfeeding under the child nutrition } \\
\text { program }\end{array}$ & Worksites; Hospitals & Nutrition \\
\hline $\begin{array}{l}\text { Child Nutrition and WIC } \\
\text { Reauthorization }\end{array}$ & $\begin{array}{l}\text { Encompasses several food programs relating to food } \\
\text { insecurity, child and maternal health, and access to healthy } \\
\text { food. School wellness policies also developed under Act. }\end{array}$ & Community; School & Nutrition \\
\hline Deficit Reduction Act (DRA) & $\begin{array}{l}\text { Provides states with flexibility to reform their Medicaid } \\
\text { programs }\end{array}$ & Health care & Healthcare \\
\hline $\begin{array}{l}\text { Employment Retirement Income } \\
\text { Security Act (ERISA) }\end{array}$ & $\begin{array}{l}\text { Ensures health plan coverage for retirees and qualified } \\
\text { beneficiaries }\end{array}$ & Worksites & $\begin{array}{l}\text { Social justice: health access, } \\
\text { health disparities, disability }\end{array}$ \\
\hline $\begin{array}{l}\text { Federal Trade Commission Act } \\
\text { (FTCAct) }\end{array}$ & Regulates food advertising & Community & Nutrition, Child protection \\
\hline $\begin{array}{l}\text { Food Conservation, and Energy } \\
\text { Act (Farm Bill) }\end{array}$ & Access to and supply of healthful foods & Community & Nutrition \\
\hline $\begin{array}{l}\text { National School Breakfast } \\
\text { Program (SBP) }\end{array}$ & $\begin{array}{l}\text { Cash assistance to states to operate nonprofit breakfast } \\
\text { program to schools and residential childcare facilitites }\end{array}$ & Schools & Nutrition \\
\hline $\begin{array}{l}\text { National School Lunch Program } \\
\text { (NSLP) }\end{array}$ & $\begin{array}{l}\text { Nutritionally balanced meals at schools and residential } \\
\text { childcare facilitites }\end{array}$ & Schools & Nutrition \\
\hline No Child Left Behind (NCLB) & $\begin{array}{l}\text { Addresses risk factor for disease: low educational attain- } \\
\text { ment and thus, higher likelihood of low SES in adulthood }\end{array}$ & Schools & Physical Activity; Education \\
\hline $\begin{array}{l}\text { Nutrition Labeling Education Act } \\
\text { (NLEA) }\end{array}$ & $\begin{array}{l}\text { Labeling of content, nutritional value and place of manu- } \\
\text { facture for food items regulated by the FDA }\end{array}$ & Community & Nutrition \\
\hline Pregnancy Discrimination Act & $\begin{array}{l}\text { Modifies the Civil Rights Act to protect breastfeeding } \\
\text { by new mothers; provide tax incentives to employers to } \\
\text { encourage breastfeeding by employees; and provide a } \\
\text { performance standard for breastpumps }\end{array}$ & $\begin{array}{l}\text { Community; Health } \\
\text { care;Worksites }\end{array}$ & Nutrition \\
\hline $\begin{array}{l}\text { Safe Accountable Flexible Efficient } \\
\text { Transportation Equity Act } \\
\text { (SAFETEA or Transportation Bill) }\end{array}$ & $\begin{array}{l}\text { Safe and accessible opportunities to commute, travel and } \\
\text { engage in PA }\end{array}$ & Community & Physical Activity \\
\hline School Bullying Policies & Discrimination against overweight children & Schools & Child protection \\
\hline Social Security Act & Provides disability insurance & Health care & Healthcare \\
\hline Zoning & $\begin{array}{l}\text { Determines whether land use favors physical activity and } \\
\text { access to healthy foods }\end{array}$ & Community & Nutrition; Physical Activity \\
\hline
\end{tabular}




\section{GAP/CHALLENGES}

Morbid obesity not recognized as disabling even when it is; ADA definitions require physiological cause

Does not make any specific recommendations or requirements to develop environments in which women can safely and privately BF; Formula distributed to mothers in hospitals after childbirth

Coordination with healthcare sectors, diverging demographics and needs of participants, and access to healthful food choices. Unhealthy foods allowed under EBT program.

Providers not adequately reimbursed under Medicaid for obesityrelated visits so disease goes untreated and preventative measures not explored

Costly COBRA benefits mean many are without healthcare coverage if laid off or upon retirement

Congress withdrew the FTC's ability to regulate "unfair" marketing/advertising to children so children inundated with ads for nutritionally poor foods and fast food establishments

Subsidizes foods of poor or minimal nutritional quality

Heavily favors packaged foods which are normally produced with excessive amounts of sugar, high fructose corn syrup, and/or salt

Heavily favors packaged foods which are normally produced with excessive amounts of sugar, high fructose corn syrup, and/or salt; Minimal restrictions on sales of competitive foods

Does not require PA, PE, or health education as part of the curricula requirements

Nutrition Facts Panel requirements do not apply to food service establishments. Food companies place diverse and uninformative symbols on the front of packaging, some touting low nutritional standards. No daily recommended value for sugar established.

Does not require the provision of lactation rooms for breastfeeding mothers

Focus on vehicular modes of transportation and limited if any consideration to safe routes, sidewalks, pedestrian and bicycle ways

Schools lack anti-bullying policies or enforcement mechanisms for existing policies

In October of 1999 deleted obesity from the recognized list of disabling conditions

Most often created without public health considerations

\section{ACTION OPTIONS}

Revise to include coverage for morbid obesity that results in disability (without the need for other physiological causes). Educate policymakers about the etiology of obesity. Bring claims under the third prong of the ADA Amendment Act of 2008's "regarded as" section when discrimination occurs because person is thought to be disabled by their weight.

Develop standards for accomodation. Make physician's prescriptions required to obtain formula in a hospital setting.

Permit and reimburse farmers/local growers to participate through use and acess of wireless payment equipment. Restrict EBT funds to nutritionally positive foods and beverages. Expand and update the definition of Foods of Minimal Nutritional Value and revise to include the entire school day and campus. Strengthen school wellness policies and increase monitoring and enforcement of them.

Provide clear reimbursement codes for obesity prevention, control and treatment, including surgery for the morbidly obese. Create medical homes for Medicaid beneficiaries.

Consider universal health care to relieve burden on employers and share cost among tax payers

The FTC should proceed under the "deceptive" prong, and Congress should restore the FTC's authority to regulate "unfair" marketing/advertising to children. The FTC should develop strong uniform nutrtition standards to be applied to marketing directed at children

Provide subsidies for the production and supply of domestic fruits and vegetables for domestic consumption. Reform subsidization of commodity crops

Require and specify foods of nutritional value that can be provided during breakfast whether through school system or outside vendors; schools and districts to adopt restrive policies on competitive foods

Permit schools to use non USDA provided foods as long as exceed minimal nutritional value and support the use of farm to school vendor contracts; school districts to implement their own policies restricting competitive foods,

Modify to require PA, PE, and health education for all students in all grade levels per the physical activity guidelines and NASPE recommendations

Include recommended daily value of added sugars on Nutrition Facts Panel; Expand to require disclosure of nutritient content in quick service restaurants; states and locales enact menu label laws. Standardize front of package quick reference symbols.

Develop standards for accomodation either mandating lactation rooms based on a formula or for implementation in the event an employer chooses to provide such services.

Increase funding when SAFETEA-LU is reauthorized.Advocate for dedicated source of funding for transit at state level.At local level, funding must be sufficient to qualify for the federal match of funds ( 20 percent must be provided).

Enact anti-bullying policies that specifically address weight bias and institute enforcement mechanisms.

Modify SSA to cover preventive (primary) and treatment (seondary and tertiary) services for obesity for children and adults.

Zone fast-food restaurants out of residential areas, zone in grocery stores and farmers markets. Zone, build, and coordinate green open spaces, safe roughts to school, sidewalks and recreation paths. 
In the absence of federal intervention, some states have consumer protection laws, under which a private litigant or the attorney general can bring a claim of unfair, misleading, or deceptive acts or practices. ${ }^{26}$ Further, school districts can limit the amount of marketing directed at children in school facilities and campuses, as discussed below.

\section{Healthy Places}

Laws and policies targeting Healthy Places address the main locus of intervention, including community, workplace, business, and transportation. ${ }^{27}$ This paper provides selected examples in different settings to recommend action items intended to ensure individuals can make healthy lifestyle choices where they are.

\section{Zoning and the Built Environment}

The United States Supreme Court upheld zoning to protect public health as a proper exercise of the government's traditional police power. ${ }^{28}$ Government officials can alter the built environment through zoning to advance their community's public health. Possible zoning ordinances to improve the availability of fresh foods at lower prices include zoning land-use for grocery stores and farmers' markets. ${ }^{29}$ Zoning strategies to reduce the availability of unhealthy options include banning fast food outlets, drive-through service and/ or formula restaurants, or zoning the density of fast food outlets through per unit space or through spacing requirements, and zoning fast-food outlets into or out of certain districts. ${ }^{30}$ For example, despite the nearly universal availability of school-provided lunch in schools, a significant percentage of high school students go offcampus to eat lunch. ${ }^{31}$ Zoning fast-food establishments away from high schools could have an impact on the quality of foods and beverages accessible and thus, consumed by these students during the school day.

The built environment also contributes to the ability of residents to engage in physical activity, for necessity, recreation, and play. ${ }^{32}$ For children, this means more safe routes to school, safe playgrounds and open green spaces to play. For adults, the Surgeon General recommends they engage in at least 30 minutes of moderate physical activity daily. Notwithstanding these recommendations, research reveals that at least half of American adults do not meet the guidelines ${ }^{33}$ and that many in fact lead sedentary lifestyles. ${ }^{34}$

Researchers and Summit participants identified societal factors that affect levels of physical activity, which include individual characteristics (demographics, household, and lifestyle characteristics, culture, time allocation, etc.); the built environment (land use patterns, transportation systems, and design features); and the social environment (societal values and pref- erences, public policies, and economic forces). ${ }^{35}$ Adult physical activity levels have declined in large part due to reduced demand for daily physical activity in leisure and in travel. The modern reliance on automobiles is being challenged by rising gas prices, environmental concerns, road congestion, increasing obesity, and decreasing physical fitness. Thus, a shift to more ubiquitous and affordable public transportation is necessary. Increased access to public transportation often provides opportunities for physical activity because most transit trips begin and/or end with walking. ${ }^{36}$

The "walkability" of a community is a key index of its healthiness. Results from a CDC study suggest that Americans who walk to and from public transit obtain an appreciable amount of daily transit-related physical activity (median of 19 minutes), with $29 \%$ of transit walkers achieving 30 or more minutes of daily physical activity solely during the commute. ${ }^{37}$ Importantly, it has been shown that walking and other less vigorous forms of physical activity are easier to sustain over time..$^{38}$ Pedestrian improvements - e.g., sidewalks, marked crosswalks, and street amenities - encourage both walking and transit use. Local governments can also require that all new construction accommodate pedestrians, and also wheelchairs, bicycles, and strollers.

\section{Transportation}

Public transit is currently seeing record-high ridership, with more than 10.3 billion riders annually, and the demand is expected to continue as gas prices remain high. ${ }^{39}$ For public transportation to grow and meet the rising demand, more funding will be required from federal, state, and local sources. Rising fuel costs and the need to upgrade vehicles and deploy information technology are driving up public transportation costs across the country. New and expanded revenue sources must be identified.

Transit systems are funded by multiple sources. Most get substantial annual funds from the federal government - called "formula" funds because they are based on population - and many also get discretionary funds for bus purchases. The discretionary funds are often referred to as earmarks. The single most important role public health advocates can play in supporting public transportation is to push for additional funding under the federal six-year transportation bill that will expire in November 2009. This bill, called the Safe, Accountable, Flexible, Efficient Transportation Equity Act: A Legacy for Users (SAFETEA$\mathrm{LU}$ ) is the primary federal legislation that authorizes programming, sets priorities, and allocates funds over a six-year period for all modes of transportation. The reauthorization of this bill is an opportunity to provide 
new funding mechanisms and significant increases in federal funding for public transportation. ${ }^{40}$

The current transportation bill for 2004-2009 included about $\$ 53$ billion for public transportation. ${ }^{41}$ Advocates say that figure will need to be increased substantially to supply the country with safe and efficient public transportation throughout the urban communities and into rural areas as well. ${ }^{42}$

Funding at the state and local levels vary widely from state to state and city to city. Some states provide a dedicated source of funding for public transportation; in those states the level of funding must rise to meet the growing demand. ${ }^{43}$ In states without a dedicated source of funding, the situation is dire as pressures for limited funds intensify. In those states, public transportation advocates would be well-advised to push for a dedicated funding source for transit and additional tools for generating revenues. ${ }^{44}$

At the local level, many agencies have a consistent revenue stream through a local sales tax or, occasionally, an income tax or other fees. Since federal funds require that a local match of 20 percent be provided, it is critical that state and local funds be sufficient to provide the match needed to qualify for federal funds.

Costs associated with the development of public transportation can be offset by factors that promote more active lifestyles, such as the following: (1) property development activities around planned transit stations; (2) decreased air pollution; and (3) potential health benefits related to increased exercise for residents living in the surrounding communities. ${ }^{45}$ Laws and policies that increase access to public transportation also improve economic opportunities in distressed communities and increase the ability for those in lower socioeconomic areas to access grocery stores, community facilities, and employment opportunities. ${ }^{46}$

\section{Workplaces}

The U.S. Census reports that in 2006, for which most current data is available, 59.7 percent of the U.S. population received health care coverage through an employer sponsored plan. ${ }^{47}$ The Centers for Medicare and Medicaid Services reported that in 2007 health care spending represented 16.2 percent of the Gross Domestic Product (GDP). ${ }^{48}$ The CDC estimates that obesity-related conditions cost employers $\$ 117$ billion in medical care and lost productivity annually; 49 this accounts for a $25 \%$ increase in medical costs between 1987 and $2001 .^{50}$ The priority of reducing health care costs has led many employers to implement workplace health promotion activities that (a) maintain employees' positive health behaviors, (b) reduce employees' risk for chronic diseases, and (c) improve employees' ability to self-manage those diseases. For instance, workplaces use cost calculators such as that provided through CDC's LEAN for Life Web site ${ }^{51}$ and health impact assessments to determine disease burden and return on investment of programming, implement initiatives to promote physical activity such as stairwells with paintings and music, onsite gyms, walking trails and green spaces, and improve employee diets by offering healthier foods in vending machines and cafeterias. Uptake of such programs is bolstered by studies demonstrating that healthier employees use less health care dollars, are absent less, and are happier employees. ${ }^{52}$

Workplace health promotion programs are primarily preventive in nature and have great potential to yield high cost savings through reduced direct expenditures for health care, workers' compensation, and disability payments, while simultaneously reducing absenteeism and increasing worker productivity. ${ }^{53}$ Employers should demand that their health insurance plans cover preventive interventions such as nutritional counseling and social support groups, gym membership when exercise is prescribed by a physician, specialized foods when prescribed by a physician, in addition to any treatment interventions recommended by medical care providers. Further, because both employers and health insurance companies have a financial interest and stake in the wellbeing of their covered employees, they should partner to reduce health care costs by improving the insured's health.

The government should also create incentives for business to promote health. It can also accomplish this by providing tax credits for businesses that offer health care and physical activity programs shown to be effective. The government should also increase the benefit amount allowable for reimbursement of public transportation use because more employees may be likely to take public transportation if they get tax incentives to do so.

\section{Healthy Society}

Healthy Societies result from the pursuit of justice as a condition of societal change at multiple levels to improve access to services, reduce disparities, and eliminate discrimination. ${ }^{54}$ For children, this domain includes schools because schools are a microcosm of their society and provide a support safety net for many children, especially those in greatest need.

\section{Schools}

School should be a place where students can buy and eat nutritious foods and engage in meaningful physical activity. Public schools must respond to directives from federal, state, and local authorities. The federal government can set standards for school nutrition and exercise and condition the receipt of funding on 
a school system's attainment of those standards..$^{55}$ States can also mandate nutrition and physical activity standards. ${ }^{56}$

\section{Nutrition}

The National School Lunch Program and the National School Breakfast Program (collectively, the NSLP $)^{57}$ provide per-meal cash reimbursements to schools that offer meals to students ostensibly meeting certain nutritional standards. ${ }^{58}$ However, despite the availability of lunch in most schools, the percentage of students who actually eat lunch offered by the school is only about 70 percent for middle school students and 60 percent for high school students. ${ }^{59}$ Whether or not students purchase or eat the school provided meal, many students also purchase products from vending machines, school stores, and snack bars.

Foods sold in competition with the NSLP in foodservice areas during the lunch periods, or "competitive foods," are allowed at the discretion of state and local authorities, ${ }^{60}$ unless they are on the list of "foods of minimal nutritional value" (FMNV). ${ }^{61}$ However, the only foods recognized as FMNV are the following: soda water, water ices, chewing gum, hard candy, jellies and gums, marshmallow candy, fondant, licorice, spun candy, and candy coated popcorn. ${ }^{62}$ This is because many products are considered exempt, ${ }^{63}$ the definition does not cover an abundance of nonnutritious foods, and the sales of FMNV are only prohibited in the food service areas during the lunch periods. ${ }^{64}$ Thus, schools can avoid this restriction by placing vending machines beyond the food service area and allow the sale of FMNV before and after the meal period. ${ }^{65}$ The federal government must expand the scope of its FMNV provision to include the whole school campus not just the cafeteria and to cover all hours during which school activities are being held whether before or after the normal school day. State and local laws can also prohibit permissive practices and include meaningful monitoring and enforcement provisions in schools' wellness policies.

State and local authorities are authorized to impose additional restrictions on the sale of competitive food. ${ }^{66}$ Many locations strengthened the nutrition standards for their school districts in response to the federal mandate to local educational agencies to establish wellness policies. ${ }^{67}$ The mandate directed local agencies to develop "goals for nutrition education, physical activity, and other school-based activities that are designed to promote student wellness." 68 The federal directives were broad recommendations and districts around the country responded in a variety of ways. ${ }^{69}$ As a result, most secondary schools still allow competitive foods and have student-accessible vend- ing machines. ${ }^{70} \mathrm{~A}$ recent study of the food in schools revealed that foods of lower nutritional value are more available than healthier foods in the nation's schools and students in low socio-economic areas have less access to healthier snacks. ${ }^{71}$

Districts should strengthen the nutritional guidelines for meals and snacks sold in their schools. Researchers found that "the most effective policies are those that prohibit sales of all beverages with caloric sweeteners (except for certain milk products), impose portion limits, apply throughout the school day, and apply to all grade levels, with age adjustments only for container sizes." ${ }^{2}$ Similarly, restrictions on food should be based on content (i.e., sugar, fat, and/or sodium) and fruits and vegetables should be made available..$^{73}$ Experience shows that by restricting what is allowed in schools, industry will work with the districts to provide products that meet the healthier criteria. ${ }^{74}$

Competitive foods and beverages are supplied by companies through individual contracts with schools or districts. States and school districts have the ability to limit what the companies can supply through limitations in the contracts. For example, when Philadelphia School District changed its beverage policy to only permit 100 percent juice, water, and milk for younger students and these same beverages, plus electrolyte replacement drinks, in high schools, their supplier was contractually obligated to comply with these guidelines. ${ }^{75}$ Another option, of course, is to ban competitive food and beverages entirely.

Moreover, schools have the power to restrict some or ban all marketing on their campuses. First Amendment analysis leads to the conclusion that school districts have broad constitutional authority to control marketing in their facilities, including restricting the marketing of all foods and beverages, or just those foods and beverages not allowed to be sold in the school according to school or district policies. ${ }^{76}$

\section{Physical Activity and Physical Education}

Some local physical education and physical activity efforts were derailed by schools simultaneously trying to comply with the No Child Left Behind Act of 2001 (NCLB). NCLB was designed to improve achievement in education through standardized testing in schools across the country. As such, physical education, health education, and physical activity requirements are not being mandated by most states. ${ }^{77}$ The National Association for Sport and Physical Education (NASPE) Shape of the Nation report found that nearly a third of the states do not mandate physical education for elementary and middle school students, and 12 states allow students to earn required physical education credits through online physical education 
courses. ${ }^{78}$ Moreover, while most states require some sort of physical education (P.E.), how often students actually engaged in physical activity varies widely. Between 17 and 22 percent of students attended P.E. each school day. Another 11 to 14 percent scheduled P.E. three or four days a week and 22 percent scheduled P.E. one day a week. ${ }^{79} \mathrm{~A}$ way to counteract this trend is for the federal government to include support for, and require, physical education, physical activity, and health education on a regular and routine basis so all school-aged children achieve the recommended 60 minutes or more of physical activity each day. This can be achieved through revisions to the authorizing language in No Child Left Behind.

\section{Access to Health Care Services}

As one of the largest health insurance programs in the United States, Medicaid serves more than 62 million people with annual expenditures exceeding $\$ 300$ billion. ${ }^{80}$ The program is jointly funded by the federal and state governments and is administered by the states under federal guidelines issued by the Centers for Medicare and Medicaid Services to serve some of the nation's most vulnerable and disadvantaged populations. ${ }^{81}$ The federal guidelines offer guidance to states on required basic services; however, states have the flexibility to offer various benefits based on the population's need. As a result, services and benefits can vary drastically among states. In recent decades, Medicaid has garnered tremendous interest from state policymakers given its impact on state budgets and the escalating prevalence and cost of preventable disease among beneficiaries. Experts estimate that states spend upwards of $\$ 21$ billion each year to treat chronic - and often preventable - conditions such as diabetes, cancer, and cardiovascular disease. ${ }^{82}$

In recent years, the passage of the Deficit Reduction Act (DRA) has made it easier for states to pilot and implement innovative reforms that target necessary health services to subsets of beneficiaries. Given the varying health needs among Medicaid beneficiaries coupled with federal and state fiscal constraints, the DRA has enabled states to increase Medicaid's efficiency and offer necessary services to those most in need, including those who require obesity prevention and treatment services.

To that end, one strategy that has garnered increasing support and should be considered is the creation of a medical home to increase disease management strategies, build beneficiary engagement, and improve care coordination among providers. ${ }^{83} \mathrm{~A}$ medical home is a health care setting that provides patients with timely, well-organized care, and enhanced access to providers. ${ }^{84}$ Through this model, beneficiaries receive a regular source of care and assistance in navigating the health care system, while states reduce the cost of care by preventing duplicative services and ensuring necessary follow-up medical care. The Commonwealth Fund 2006 Health Care Quality Survey found that when adults have health insurance coverage and a medical home, racial and ethnic disparities in access and quality are reduced or even eliminated. ${ }^{85}$ Patients with medical homes are more likely to receive preventative care, whether or not they are insured. ${ }^{86}$

In addition to the creation of medical homes, providing affordable medical services through community health centers would improve the health of community members and increase their ability to self-mange chronic conditions by providing them with access to health resources information. ${ }^{87}$ Community health centers play an integral role in the health care safety net and provide care to the uninsured so that emergency room visits can be minimized. Providing individuals with such a resource is cost efficient and will allow care for obesity-related services when they are otherwise not available.

\section{Reimbursement for Obesity Prevention and Care}

Summit participants overwhelmingly suggested that both public and private health insurance should cover obesity treatment, prevention, and care. This means that reimbursement codes for obesity-related visits are necessary. Research reveals that while certain reimbursement codes exist, the issue is whether insurers recognize and reimburse for the codes used and whether they do so for obesity not for another disease, like hypertension, that providers use to treat obesity issues. ${ }^{88}$ Medicaid managed care contracts generally do not highlight obesity prevention and treatment strategies ${ }^{89}$ Thus, it is unclear whether state programs specifically recognize, compensate, or reward providers who emphasize appropriate obesity interventions.

Some states may create further barriers to such care by restricting the number of compensated visits for certain care, strictly requiring prior authorization for treatment that is medically indicated, and prohibiting coverage for certain procedures. ${ }^{90}$ These restrictions coupled with low payment rates have a considerable negative impact on prevention and care of obesity.

One solution would be for states to require public and private health insurance provide clear reimbursement codes for obesity and obesity-related prevention and care for both pediatric and adult patients. States should also legislate against the barriers described above to give providers the ability to address obesity and be reimbursed for such care. Another solution is to bundle obesity prevention and treatment services 
into one package as is done for certain "disease management" payment and coverage. ${ }^{91}$

\section{Prevention and Treatment: Bariatric Surgery}

Bariatric surgery has been recognized by the NIH as valuable for reducing the disease burden of obese patients. ${ }^{92}$ The Mayo Clinic found that bariatric surgery reduces cardiovascular risk ${ }^{93}$ and metabolic syndrome $^{94}$ in patients. Public and private insurance covers such surgery if certain criteria are met, such as being diagnosed with a comorbidity or having previously and unsuccessfully attempted to treat obesity through medically supervised care over an extended period of time. ${ }^{95}$ Such criteria can function as an impediment to coverage for morbidly obese patients and such prerequisites should be eased. States can enact laws to mandate public and private health insurance cover surgery based solely on the diagnosis of morbid obesity.

Even when such criteria are met, studies show that socioeconomic characteristics are a function of who actually receives bariatric surgery. ${ }^{96}$ Patients on Medicaid who qualify for bariatric surgery do not receive it to the extent that those with private insurance do. While Medicaid patients have significantly higher BMIs and more severe comorbid conditions, lower income and public insurance were associated with decreased odds for selection for bariatric surgery. ${ }^{97}$ Thus, those who could benefit from bariatric surgery most are not obtaining such treatment.

Researchers theorize that this under-representation is caused by an inability to obtain approval for surgery from various Medicaid agencies and reduced payment to physicians and hospitals for the care of Medicaid patients. ${ }^{98}$ Many practices will not take publicly funded patients due to low reimbursement rates. This negatively impacts preventative treatment, care, and access to services, including surgery.

Patients with publicly funded insurance have greater incidence of serious comorbid conditions at the outset, are at higher risk for complications from bariatric surgery and require more extensive post-operative care. This is likely due to decreased access to health care and preventative services over the life course. Increased preventative care is clearly warranted. Investing in prevention will produce direct medical cost savings and avoid the toll obesity and related disease processes take on human life. States should regulate Medicaid programs to focus on preventative measures.

\section{Disparities}

There is lack of a cohesive national strategy to eliminate racial and ethnic health disparities. Disparities in health care are defined as racial or ethnic differences in the quality of health care that are not due to access- related factors, clinical needs, preferences, or appropriateness of interventions..$^{99}$ Even among patients insured at the same levels, research shows that racial and ethnic minority patients face barriers to services and receive less care than their Caucasian counterparts. This cuts across many health issues, and obesity is high among them.

The lack of access to health care is one overarching issue for many racial and ethnic minorities, who are more likely to lack health insurance coverage or be underinsured compared to Caucasians. ${ }^{100}$ People of color make up about 30 percent of the U.S. population, but they comprise over half of the nation's uninsured. ${ }^{101}$ For American Indian populations living in cities, securing access to Medicaid coverage has proven especially difficult. ${ }^{102}$ Minority individuals are more likely to access health care in public hospitals and community health centers. ${ }^{103}$ However, minority communities have fewer health care resources such as hospitals, clinics, and nursing homes. ${ }^{104}$ These disparities result in an increased incidence and prevalence of obesity-related complications, including increased rates of co-morbidities due to lack of access to care, reduced services, and an absence of information.

States can improve access and coverage for racial and ethnic minorities by enacting laws specifically aimed at improving Medicaid coverage and reimbursement rates, as discussed in the preceding sections. Improving funding reimbursement rates by Medicaid for obesity-related visits could also improve access to providers for whom reimbursement is currently low. This would also allow providers to spend more time providing necessary care and engaging patients in informative discussions. Further, the government could provide physicians with financial incentives that encourage adherence to age and gender appropriate disease screenings and are linked to positive disease control outcomes, regardless of race or ethnicity. ${ }^{105}$ Finally, the federal, state, and local governments should provide funding to hospitals in financially vulnerable areas because low Medicaid reimbursement rates and uninsured care threaten their stability. ${ }^{106}$

The American Indian communities in the U.S. are in a particularly precarious position with respect to obesity and diabetes rates, which are among the highest in the world. ${ }^{107}$ This area is a recognized gap in obesity prevention and control efforts and must be a priority research area going forward. Federal, state, and local programs directed at obesity prevention and control must pay particular attention to ensure that American Indians benefit from these improvements. Due to economic difficulties and geographic isolation of some reservations, policymakers should partner with tribal governments, American Indian organiza- 
tions, and community members to ensure the reach of improvement efforts extend to American Indian communities. One area where governments can immediately act is to strengthen the nutritional quality of the USDA food distribution program directed at American Indian communities. This program provides a safety net for many American Indians. However, the nutritional quality of many of the commodity items is poor and must be improved. ${ }^{108}$ In addition, because most American Indian school children on reservations eat two meals a day in school, ${ }^{109}$ the nutrition guidelines in such schools must be strong and the quality of commodity foods in these schools must be improved.

\section{Discrimination Based on Weight}

Beyond obesity and nutrition policy, addressing and reducing discrimination based on weight is necessary for equality in a healthy society. Bias and discrimination result in discriminatory practices against the perceived "lesser" class. This perpetuates the problem through reduced utilization of health care, reduced coverage by health insurance, and public policies that do not match the severity of the problem.

Because it is not illegal to discriminate against people based on their weight, obese people suffer from discriminatory practices by employers, medical professionals, and health insurance companies, with little to no legal recourse..$^{110}$ One way states can protect their citizens against weight discrimination is to follow the lead of Michigan and revise their anti-discrimination laws to include weight as a protected class. ${ }^{111}$

Discrimination in employment is of particular concern due to the fact that it is a source of income, stability, and for most, health insurance. Studies confirm that obese persons are less likely to be hired, are more harshly disciplined, paid less, and have been terminated for failure to lose weight. ${ }^{112}$ Because Congress has legislated in the field of employment discrimination several times prior, this is a viable avenue to address weight discrimination. Congress should enact a Weight Discrimination in Employment Act ${ }^{113}$ that replicates the Age Discrimination in Employment Act of $1967 .{ }^{114}$

People who have been discriminated against have attempted to sue under two existing provisions, the American with Disabilities Act (ADA) of $1990^{115}$ and the Rehabilitation Act (RA) of 1973, ${ }^{116}$ with little success. The initial and very significant drawback of suing under these provisions is that a potential plaintiff must claim that he or she is disabled. The ADA defines disability as (a) a physical or mental impairment that substantially limits one or more of the major life activities of such individual; (b) a record of such an impairment; or (c) being regarded as having such an impairment. ${ }^{117}$

Most courts have found that to constitute an impairment under the first two prongs of the ADA, a person's obesity, even morbid obesity, must be the result of a physiological condition (like diabetes). ${ }^{118}$ Congress should amend the ADA definition of disability to explicitly include obesity, and the Equal Employment Opportunity Commission should redefine "impairment" to include obesity not based on a physiological condition. This would still require people to allege that they are actually disabled, but morbidly obese individuals who are disabled due to their weight would be covered under the ADA comparable to any other disability.

The third prong of the ADA may prove to be more effective in combating discriminatory practices against overweight individuals. Congress recently passed the ADA Amendments Act of 2008, ${ }^{119}$ which seeks to reinstate a "broad view" of the third prong's "regarded as" language, ${ }^{120}$ as a direct reaction to increasingly limiting case law interpreting this definition. ${ }^{121}$ Through this amendment, Congress sought to reinstate the rationale of a Supreme Court case annunciating a broad interpretation of the third prong. This case explained third prong coverage as follows: "a person with some kind of visible physical impairment which in fact does not substantially limit that person's functioning.' Such an impairment might not diminish a person's physical or mental capabilities, but could nevertheless substantially limit that person's ability to work as a result of the negative reactions of others to the impairment." ${ }^{22}$ This sounds directly applicable to those who suffer from weight discrimination. The Act went into effect on January 1, 2009, but legal action under this revised understanding of the third prong's intent has yet to be tested in court. However, this would be a less stigmatizing and potentially fruitful way that overweight and obese people who are not impaired, but have been treated as if they were, could proceed to secure equal rights. ${ }^{123}$

\section{Conclusion}

Public health legal preparedness for obesity prevention and control is essential at the federal, tribal, state, local, and community levels. Law and policymakers and public health practitioners have many domains to address and consider when developing, implementing, and evaluating obesity prevention and control strategies and interventions. In the healthy lifestyles domain, the goal is to make the default environment one that fosters healthy lifestyles by making the healthy option the easier choice. Action items include altering the farm subsidies to increase the affordability of 
produce and lean meats. Marketing practices targeting children must be regulated at the federal level, and the FTC should be authorized to regulate the youth marketing and advertising practices of the food and beverage industries.

The healthy places domain recognizes that the surrounding community, workplace, and transportation options influence the ability to make healthy choices. Communities can use their power to zone to protect public health and organize the built environment to foster healthy choices through increased access to supermarkets and farmers' markets, and fewer fastfood outlets and corner stores predominantly carrying processed food items. The federal, state, and local governments should support public transportation to increase residents' access to the community, foster physical activity, and address environmental health concerns. Finally employers must be incentivized to support healthy lifestyles in the workplace to prevent obesity and obesity-related diseases. This would result in reduced direct expenditures for health care, workers' compensation, and disability payments, while simultaneously reducing absenteeism and increasing worker productivity.

The final domain of healthy society addresses the complex societal causes and contributors to obesity, disparities and discrimination. Under this domain, federal, tribal, state, and local policies for school nutrition standards and increased physical activity must be strengthened. Further federal and state authorities can work to increase access to health care, including preventative services, through increased reimbursement for obesity-related care for Medicaid beneficiaries. Specific racial, ethnic, and socioeconomic disparities that result from both the lack of access to services and contribute to obesity are challenges on their own. This area requires more research and must be directly addressed. Similarly, weight discrimination must be addressed to ensure social justice and adequate care for those currently suffering from obesity.

Governments are faced with many critical issues with respect to public health, health care access, and obesity prevention and control. There are legal action options available at every level of government. At the federal and state level, policymakers should enact antipreemption provisions setting a floor not a ceiling on the initiatives states and localities can adopt. Local efforts have been impressive but strong state, tribal, and federal efforts are required to adequately address the obesity crisis in the United States. It is imperative that governments act now to make real change. Deregulations, ${ }^{124}$ attributions of personal responsibility ${ }^{125}$ and nutrition educational campaigns ${ }^{126}$ have proven ineffective to prevent and control obesity. It is time to address obesity as a disease, like any other, and enact legal action items that will directly reduce the disease burden and prevent future crisis. The future of our country's health depends on the implementation of legal action items now.

Acknowledgements

The authors would like to acknowledge the contributions of Nina Walfoort, Joyal Mulheron, and Jeff Bachar.

References

1. See L. O. Gostin and J. L. Pomeranz, "The Vital Domains of Obesity Prevention and Control: Healthy Lifestyles, Healthy Places, and Healthy Societies," Assessing Laws and Legal Authorities for Obesity Prevention and Control.

2. A. D. Moulton, R. N. Gottfried, R. A. Goodman, A. M. Murphy, and R. D. Rawson, "What Is Public Health Legal Preparedness?" Journal of Law, Medicine छ๋ Ethics 31, no. 4 (2003): $1-12$.

3. See Gostin and Pomeranz, supra note 1.

4. Editorial, "Harvesting Cash," Washington Post, available at <http://www.washingtonpost.com/wp-srv/nation/interactives/ farmaid/> (last visited March 18, 2009).

5. Editorial, "Making the Most of a Subsidy," Washington Post, available at <http://www.washingtonpost.com/wp-dyn/content/graphic/2006/07/03/GR2006070300057.html> (last visited March 18, 2009).

6. J. J. Putnam, J. E. Allhouse, and L. S. Kantor, "U.S. Per Capita Food Supply Trends: More Calories, Refined Carbohydrates, and Fats," Food Reviere 25, no. 3 (2002): 2-15.

7. Leopold Center for Sustainable Agriculture, Iowa State University, Food Facts: Results from Marketing and Food Systems Research, March 2008, at 8, available at <http://www.leopold. iastate.edu/research/marketing_files/food/Food_Facts_0308. pdf> (last visited March 18, 2009).

8. D. Swenson, Leopold Center for Sustainable Agriculture, Iowa State University, The Economic Impacts of Increased Fruit and Vegetable Production and Consumption in Iowa: Phase II, 2006, available at <http://www.leopold.iastate.edu/pubs/staff/ files/health_0606.pdf> (last visited March 18, 2009).

9. A. F. Brown, R. B. Vargas, A. Ang, and A. R. Pebley, "The Neighborhood Food Resource Environment and the Health of Residents with Chronic Conditions: The Food Resource Environment and the Health of Residents," Journal of General Internal Medicine 23, no. 8 (2008): 1137-1144.

10. Id.

11. J. N. Bodor, D. Rose, T. A. Farley, C. Swalm, and S. K. Scott, "Neighbourhood Fruit and Vegetable Availability and Consumption: The Role of Small Food Stores in an Urban environment," Public Health Nutrition 11, no. 4 (2008): 413-420.

12. F. Li, P. A. Harmer, B. J. Cardinal, M. Bosworth, A. Acock, D. Johnson-Shelton, and J. M. Moore, "Built Environment, Adiposity, and Physical Activity in Adults Aged 50-75," American Journal of Preventative Medicine 35, no. 1 (2008): 38-46.

13. $I d$.

14. Federal Trade Commission, "Food Industry Marketing to Children Report: Orders to File Special Report; FTC Matter No.: P064504," available at <http://www.ftc.gov/os/6b_orders/ foodmktg6b/index.shtm> (last visited March 18, 2009).

15. Federal Trade Commission, Marketing Food to Children and Adolescents, July 2008, available at <http://www.ftc.gov/ os/2008/07/P064504foodmktingreport.pdf $>$ (last visited March 18, 2009).

16. Id.

17. J. L. Harris, J. L. Pomeranz, T. Lobstein, and K. D. Brownell, “A Crisis in the Marketplace: How Food Marketing Contributes to Childhood Obesity and What Can Be Done," Annual Review of Public Health (citing studies) (in press). 
18. Federal Trade Commission Act, 15 U.S.C. $\$ \S 41-58$ (as amended).

19. 46 FR 48710, Children's Advertising, codified at 16 CFR 461 (October 2, 1981)

20.15 U.S.C. $45(\mathrm{~h})$.

21. M. M. Mello, "Federal Trade Commission Regulation of Food Advertising to Children: Possibilities for a Reinvigorated Role," working paper, 2008.

22.J. Pomeranz, "Television Food Marketing to Children Revisited: The Federal Trade Commission Has the Constitutional and Statutory Authority to Regulate," working paper, 2009.

23. IOM, Food Marketing to Children and Youth: Threat or Opportunity, 2006, at 309.

24. D. Kunkel, B. L. Wilcox, J. Cantor, E. Palmer, S. Linn, and P. Dowrick, Report of the APA Task Force on Advertising and Children: Psychological Issues in the Increasing Commercialization of Childhood, February 20, 2004, at 16.

25. D. Eisenberg, J. McDowell, L. Berestein, D. Tsiantar, and E. Finan, "It's an Ad, Ad, Ad, Ad World," Time 160, no. 10 (2002):38-42.

26. See e.g., Williams v. Gerber Products Co., 2008 U.S. App. LEXIS 8599 (April 21, 2008 9th Cir) (private litigant successfully brought action under California's consumer protection laws for deceptive packaging of Gerber food product for toddlers). See, e.g., NY CLS Gen Bus $\$ 349$ (2008) (Deceptive acts and practices unlawful; attorney general may bring an action in the name and on behalf of the people of the state of New York).

27. See Gostin and Pomeranz, supra note 1.

28. Village of Euclid v. Ambler Realty, 272 U.S. 365 (1926).

29. K. Hodgson, Regulation of Food Access through Comprehensive Planning and Zoning," Virginia Tech, Urban Affairs and Planning, Alexandria Center, April 17, 2008 (unpublished manuscript).

30. J. S. Mair, M. W. Pierce, and S. P. Teret, The Use of Zoning to Restrict Fast Food Outlets: A Potential Strategy to Combat Obesity, October 2005, available at <http://www.publichealthlaw. net/Zoning\%20Fast $\% 20$ Food $\% 20$ Outlets.pdf $>$ (last visited March 18, 2009).

31. J. Delva, P. M. O’Malley, and L. D. Johnston, “Availability of More-Healthy and Less-Healthy Food Choices in American Schools: A National Study of Grade, Racial/Ethnic, and Socioeconomic Differences," American Journal of Preventive Medicine 33, no. 4, Supplement (2007 ): S226-S239.

32. W. C. Perdue, L. A. Stone, and L. O. Gostin, The Built Environment and Its Relationship to the Public's Health: The Legal Framework," American Journal of Public Health 93, no. 9 (2003): 1390-1394.

33. L. M. Besser and A L. Dannenberg, "Walking to Public Transit Steps to Help Meet Physical Activity Recommendations," American Journal of Preventive Medicine 29, no. 4 (2005): 273-280.

34. F. Li, P. A. Harmer, B. J. Cardinal, M. Bosworth, A. Acock, D. Johnson-Shelton, J. M. Moore, "Built Environment, Adiposity, and Physical Activity in Adults Aged 50-75," American Journal of Preventive Medicine 35, no. 1 (2008): 38-46.

35. R. J. Stokes, J. MacDonald, and G. Ridgeway, Estimating the Effects of Light Rail Transit on Health Care Costs," Health Place 14, no. 1 (2008): 45-58.

36. See Besser and Dannenberg, supra note 33.

37. Id.

38. See Stokes, MacDonald, and Ridgeway, supra note 35

39. American Public Transportation Association, 10.3 Billion Trips Taken On Public Transportation Ridership In 2007 - The Highest Level in 50 Years; Ridership Increased as Gas Prices Remained High, News Release, March 3, 2008, available at <http://www.apta.com/media/releases/080310_ridership.cfm> (last visited March 18, 2009).

40. Report of the National Surface Transportation Policy and Revenue Study Commission: Transportation for Tomorrow, January 2008.

41. 23 U.S.C. 101 et seq.
42. U. S. PIRG Education Fund, A Better Way to Go: Meeting American 21st Century Challenges with Modern Public Transit, March 2008, at 57.

43. Id., at 40 .

44. Future Highway and Public Transportation Financing, prepared for National Chamber Foundation, prepared by Cambridge Systematics, Inc. with Mercator Advisors, LLC, Alan E. Pisarski.

45. See Stokes, MacDonald, and Ridgeway, supra note 35.

46. National REACH Coalition, Creating More Equity in Health: A Comprehensive Approach to Health Reform, July 2008.

47. U.S. Department of Health and Human Services, Office of the Assistant Secretary for Planning and Evaluation, Overview of the Uninsured in the United States: An Analysis of the 2007 Current Population Survey, September 2007.

48. M. Hartman, A. Martin, P. McDonnell, and A. Catlin, Centers for Medicaid and Medicare Services, "National Health Spending in 2007: Slower Drug Spending Contributes to Lowest Rate of Overall Growth Since 1998" Health Affairs 28, no. 1 (2000): 246-261.

49. See CDC's LEAN for Life, available at <www.cdc.gov/leanforlife $>$ (access protected).

50. K. E. Thorpe, C. S. Florence, D. H. Howard, and P. Joski, "The Impact of Obesity on the Rise in Medical Spending" Health Affairs Web Exclusive, Supplement (2004): w4-480-w4-86.

51. Id.

52. M. Reyes, "Obesity in Workplaces," Presentation for CDC Lean for Life, 2008.

53. Prevention Institute, Restructuring Government to Address Social Determinants of Health, May 2008.

54. See Gostin and Pomeranz, supra note 1.

55. L. Gostin, Public Health Law: Power, Duty, Restraint, 2nd ed. (Berkeley: University of California Press, 2008)

56. P. Moran, J. Pomeranz, and M. M. Mello, Policies Affecting Access to Sugar-Sweetened Beverages in Schools: A Legal and Regulatory Review, Report to the Robert Wood Johnson Foundation, 2006

57. The National School Lunch Program and the National School Breakfast Program have identical "competitive food" standards and thus are, for purposes of this paper, treated as one program. See 7 C.F.R. \$ 210.12 (National School Lunch Program Competitive Food rules) and 7 C.F.R. § 220.12 (National School Breakfast Program Competitive Food rules).

58. USDA Memorandum, National School Lunch Program/School Breakfast Program, January 16, 2001.

59. See Delva, O’Malley, and Johnston, supra note 31.

60. 7 CFR 210.11(a)(1)

61. 7 CFR 210.11 (b)

62. 7 CFR 210 Appendix B (a).

63. 7 CFR 210 Appendix B (b).

64. 7 CFR 210.11(a).

65. S. Fox, A. Meinen, M. Pesik, M. Landis, P. L. Remington, Competitive Food Initiatives in Schools and Overweight in Children: A Review of the Evidence," WMJ 104 (2005): 38-43.

667 CFR 210.11(b).

67. Public Law 108-265 [S. 2507], June 30, 2004.

68. Public Law 108-265 [S. 2507], June 30, 2004 § 204 (a)(1).

69. See Moran, Pomeranz, and Mello, supra note 56.

70. H. Patrick and T. A. Nicklas, A Review of Family and Social Determinants of Children's Eating Patterns and Diet Quality," Journal of the American College of Nutrition 24, no. 2 (2005): 83-92.

71. See Delva, O'Malley, and Johnston, supra note 31.

72. M. M. Mello, J. Pomeranz, and P. Moran, "The Interplay of Public Health Law and Industry Self-regulation: The Case of Sugar-Sweetened Beverage Sales in Schools," American Journal of Public Health 98, no. 4 (2008): 595-604.

73. M. Story, K. M. Kaphingst, and S. French, "The Role of Schools in Obesity Prevention," Future of Children 16, no. 1 (2006): 109-142.

74. See Moran, Pomeranz, and Mello, supra note 56. J. E. Whatley Blum, A. M. Davee, R. L. Devore, C. M. Beaudoin, P. L. 
Jenkins, L. A. Kaley, D. A. Wigand, "Implementation of LowFat, Low-Sugar, and Portion-Controlled Nutrition Guidelines in Competitive Food Venues of Maine Public High Schools," Journal of School Health 77, no. 10 (2007): 687-693.

75. See Moran, Pomeranz, and Mello, supra note 56.

76. S. K. Graff, "First Amendment Implications of Restricting Food and Beverage Marketing in Schools," ANNALS of the American Academy of Political and Social Science 615 (2008): 157-177.

77. H. Trickey, "No Child Left Out of the Dodgeball Game?" CNN. com (Health), August 24, 2006, available at <http://www.cnn. com/2006/HEALTH/08/20/PE.NCLB/index.html> (last visited March 18, 2009).

78. National Association for Sport and Physical Education (NASPE), "2006 Shape of the Nation Report," available at <http://www.aahperd.org/naspe/ShapeOfTheNation/> (last visited March 18, 2009).

79. Id.

80. National Governors Association and National Association of State Budget Officers, The Fiscal Survey of the States, June 2008, available at $<\mathrm{http}$ ///www.nasbo.org/Publications/PDFs/ Fiscal $\% 20$ Survey $\% 20$ of $\% 20$ the $\% 20$ States $\% 20 J u n e \% 202008$. pdf> (last visited March 19, 2009). Id.

81. Department of Health and Human Services, Centers for Medicare and Medicaid Services, Medicaid Fact Sheet, Center for Medicaid and State Operations, Medicaid At-A-Glance 2005: A Medicaid Information Source, available at <http://www. cms.hhs.gov/MedicaidGenInfo/Downloads/MedicaidAtAGlance2005.pdf> (last visited March 19, 2009).

82. E. A. Finkelstein, I. C. Fiebelkorn, and G. Wang, "National Medical Spending Attributable to Overweight and Obesity: How Much, and Who's Paying?" Health Affairs W3 (2003): 219-226.

83. National REACH Coalition, Creating More Equity in Health: A Comprehensive Approach to Health Reform, July 2008, NGA Center Issue Brief, Medicaid Redesigned: State Innovations in Health Coverage andDelivery, March 2008, availableat $<\mathrm{http}: / /$ www.nga.org/Files/pdf/0803MEDICAIDREDESIGNED. PDF> (last visited March 19, 2009). NGA Center Issue Brief, Creating Healthy States: Healthy Living in the Medicaid Program, March 2006, available at <http://www.nga.org/Files/ pdf/0608CREATINGHEALTHYSTATESMEDICAID.PDF> (last visited March 19, 2009).

84. A. C. Beal, M. M. Doty, S. E. Hernandez, K. K. Shea, and K. Davis, Closing the Divide: How Medical Homes Promote Equity in Health Care, Results from The Commonwealth Fund 2006 Health Care Quality Survey, vol. 62 (June 27, 2007).

85. Id.

86. Id.

87. $I d$.

88. S. Wilensky, R. Whittington, and S. Rosenbaum, Strategies for Improving Access to Comprehensive Obesity Prevention and Treatment Services for Medicaid-Enrolled Children, Policy 9. $I d$.

90. Id.

91. Id.

92. NIH Consensus Statement, Gastrointestinal Surgery for Severe Obesity 9, no. 1 (March 25-27, 1991): 1-20.

93. J. A. Batsis, A. Romero-Corral, M. L. Collazo-Clavell, M. G. Sarr, V. K. Somers, L. Brekke, and F. Lopez-Jimenez, "Effect of Weight Loss on Predicted Cardiovascular Risk: Change in Cardiac Risk after Bariatric Surgery," Obesity 15, no. 3 (2007): 772-784.

94. J. A Batsis, A. Romero-Corral, M. L. Collazo-Clavell, M. G. Sarr, V. K. Somers, and F. Lopez-Jimenez, "Effect of Bariatric Surgery on the Metabolic Syndrome: A Population-Based, Long-Term Controlled Study," Mayo Clinic Proceedings 83, no. 8 (2008): 897-907.

95. J. G. Hodge, A. M. Garcia, and S. Shah, "Legal Themes Concerning Obesity Regulation in the United States: Theory and Practice," Australia and New Zealand Health Policy 5:14 (2008).
96. E. H. Livingston, C. K. Ko, Socioeconomic Characteristics of the Population Eligible for Obesity Surgery," Surgery 135 (2004): 288-296.

97. J. W. Alexander, H. R. Goodman, L. R. Martin Hawver, and L. James, "The Impact of Medicaid Status on Outcome after Gastric Bypass," Obesity Surgery 18, no. 10 (2008): 1241-1245. 98. Id.

99. Institute of Medicine, Summary. Unequal Treatment: Confronting Racial and Ethnic Disparities in Health Care, National Academy of Sciences, 2003.

100. National REACH Coalition, Creating More Equity in Health: A Comprehensive Approach to Health Reform, July 2008, at 12.

101. $I d$.

102. J. R. Joe, "The Rationing of Healthcare and Health Disparity for the American Indians/Alaska Natives," in Unequal Treatment: Confronting Racial and Ethnic Disparities in Health Care, National Academy of Sciences, 2003.

103. See National REACH Coalition, supra note 100.

104. D. P. Andrulis and L. M. Duchon, Hospital Care in the 100 Largest Cities and Their Suburbs, 1996-2002: Implications for the Future of the Hospital Safety Net in Metropolitan America, Robert Wood Johnson Foundation, August 2005.

105. See Institute of Medicine, supra note 99.

106. See National REACH Coalition, supra note 100.

107. M. Story, M. Evans, R. R. Fabsitz, T. E. Clay, B. H. Rock, and B. Broussard, "The Epidemic of Obesity in American Indian Communities and the Need for Childhood Obesity Prevention Programs," American Journal of Clinical Nutrition 69, Supplement (1999): 747S-754S.

108. $I d$.

109. Id.

110. R. Puhl and K. D. Brownell, "Bias, Discrimination, and Obesity," Obesity Research 9, no. 12 (2001): 788-805.

111. State Representative Byron Rushing recently introduced a bill in Massachusetts making it illegal to discriminate based on size (i.e., weight and height). See MA House Bill No. 1844 (2007).

112. J. Fikkan and E. Rothblum, "Weight Bias in Employment," in K. D. Brownell, R. B. Puhl, M. B. Schwartz, and L. C. Rudd, eds., Weight Bias: Nature, Consequences, and Remedies. (New York: Guilford, 2005): at 15-25.

113. J. L. Pomeranz, "A Historical Analysis of Public Health, the Law, and Stigmatized Social Groups: The Need for Both Obesity and Weight Bias Legislation," Obesity 16, Supplement 2 (November 2008): S93-S103.

114. 29 U.S.C. $\$ 621$ et seq.

115. 42 U.S.C. $\$ 12101$ et seq.

116. 29 U.S.C. $\$ 701$ et seq.

117. 42 U.S.C. $\$ 12102(2)$.

118. EEOC v. Watkins Motor Lines, Inc., 463 F.3d. 436, 443 (6th Cir. 2006).

119. ADA Amendments Act of 2008, Public Law 110-325 (September 25, 2008)

120. See S. $3406 \$ 2(b)(3) ;$ H.R. $3195 \$ 2(b)(3)$.

121. See, e.g., Sutton v. United Air Lines, Inc., 527 U.S. 471, 489494 (1999).

122. School Board of Nassau Co., FL v. Arline, 480 U.S. 273, 283284 (1987) (citing S. Rep. No. 93-1297, at 64) (internal citations omitted).

123. See Pomeranz, supra note 113.

124. FTC Improvements Act of 1980,15 U.S.C. $\$ 57 \mathrm{a}(\mathrm{h})$ (FTC Improvements Act of 1980 took away FTC's authority to "promulgate any rule" based on a determination that children's advertising constitutes an unfair act or practice.)

125. See, e.g., Personal Responsibility in Food Consumption Act, HR 339, 108th Cong. (2004); Personal Responsibility in Food Consumption Act of 2005, HR 554, 109th Cong. (2005); Commonsense Consumption Act of 2005, S. 908, 109th Cong. (2005); Commonsense Consumption Act of 2007 (Introduced in House) HR 2183 IH (110th CONGRESS) 1st Session; Com- 
monsense Consumption Act of 2007 (Introduced in Senate) S 1323 IS (110th CONGRESS) 1st Session.
126. See, e.g., USDA, "MyPyramid," available at <http://www. mypyramid.gov/> (last visited March 19, 2009). 